\title{
HABITAT DESIRABILITY MODELING OF CHEETAH (ACINONYX JUBATUS VENATICUS) USING MAXIMUM ENTROPY MODEL IN CENTRAL IRAN (A CASE STUDY: YAZD PROVINCE- DAREH ANJIR WILDLIFE REFUGE)
}

\author{
MOROVATI, M. ${ }^{1}$ - PANAHANDEH, M. ${ }^{2 *}-$ ROUSTA, Z. ${ }^{3}-$ SHORAKAEI, M. J. ${ }^{4}$ \\ ${ }^{I}$ Department of Environment, Faculty of Agriculture and Natural Resources, Ardakan \\ University, Ardakan, Yazd Iran \\ (phone: +98-913-335-2714) \\ ${ }^{2}$ Research deputy of Guilan branch of the Academic Center for Education, Culture and \\ Research (ACECR). Rasht, Iran. \\ (phone: +98-911-132-8219) \\ ${ }^{3}$ Department of Environmental Science, Faculty of Environment and Energy, Science and \\ Research Branch, Islamic Azad University, Tehran, Iran \\ (phone: +98-917-855-4058) \\ ${ }^{4}$ Environmental Protection Office of Yazd Province . \\ (phone: +98-913-254-8011) \\ *Corresponding author \\ e-mail:maryamp_2006@yahoo.com \\ (Received $16^{\text {th }}$ Nov 2014; accepted $20^{\text {th }}$ Dec 2014)
}

\begin{abstract}
The Asiatic cheetah (Acinaryx jubatus venaticus) is an endangered species that only remains in the wild in Iran. Dareh Anjir wildlife refuge in central Iran is one of the best and the most secure habitats for this species. This study used the MAXENT method to study data from 2011 to 2013 to determine the suitability of habitat and specify factors affecting the presence of cheetahs. Environmental variables used in modeling were: height layers, slope, prey distribution (Gazella bennettii, Ovis orientalis, Capra aegagrus), distance to water resources, vegetation, distance to villages, distance to roads (asphalt, unpaved), distance to mines, and distance to railways. The results show that the most important factor affecting the presence of the cheetah is distance-to-water-resources. The parameters of prey distribution and level of vegetation were identified as the most effective factors for determining a plan to preserve and predict desirable areas for the presence of cheetahs. These predictions indicate that central and southeastern portions of Dareh Anjir wildlife refuge are the most suitable for the cheetah. The results of this study can be used to develop protective and managerial strategies to increase desirable habitats in Yazd province.
\end{abstract}

Keywords: Acinonyx jubatus venaticu, Habitat Desirability, Dareh Anjir Wildlife Refuge, MaxEnt, Maximum Entropy

\section{Introduction}

The Asiatic cheetah (acinonyx jubatus venaticus) is a rare and endangered Iranian carnivore. This creature has disappeared from former habitats in other Asian countries and remains in the wild only in Iran. For this reason, it is commonly known as the Iranian cheetah. The Iranian cheetah is the second most-endangered cat in the world after the Amour panther, of which only 30 to 40 remain in the wild (Zamani, 2010). Harrington (1971) states that the number of Iranian cheetahs before WWII was about 
400 and they were spread across the deserts and step regions of eastern Iran and some western areas near the Iraqi border.

In recent years, poaching, habitat degradation agriculture development, and a decrease in prey have caused its numbers to strongly decline to the point where an accurate estimation of the current population is not available.

Understanding major factors affecting the decline of the cheetah population is critical and requires an examination of current cheetah habitats to identify the biological and non-biological factors affecting them. Identification of potential habitats and how to improve and revive the remaining habitats require investigation of the factors effecting species distribution and habitat selection.

Researchers and wildlife managers often map probable and present distributions of an endangered species to establish preserves (Baldwin, 2009). Habitat modeling methods were first developed in the 1970s and were quickly employed in wildlife management (Mack et al., 1997; Anderson et al., 2000). The use of these methods allow large-scale estimation of habitat desirability without the need to gather details of physiological characteristics and species behavior (Morrison et al., 1992). One way to identify environmental parameters and their interactions is to apply ecological modeling to species distribution (Treves et al., 2002; Naturalium, 2009). Such methods are used to: (1) determine species habitat desirability (Vantoor et al., 2011); (2) predict species development trends in a region (Giovanelli et al., 2010); and (3) predict high-risk regions from competition between wildlife species and humans (Leung et al., 2002). Among the methods of modeling wildlife habitats (Levins, 1966), maximum entropy modeling has been shown to perform as well as or better than other methods. This algorithm is a common machine-learning algorithm supported by the thermodynamic regulations of ecological processes (Phillips et al., 2006). It is useful for mapping species distribution and habitat density (Baldwin, 2009). It has high prediction power, even for areas of low species presence and is widely used by researchers because it saves time and is cost effective (Hoffman et al., 2008; Wilting et al., 2010).

The present study used MAXENT maximum entropy for modeling geographical species distribution to model the suitability of the current habitat of the Asiatic cheetah in the Dareh Anjir wildlife refuge in Yazd, Iran. It examined how the presence of the cheetah is affected by environmental variables and developed probabilistic habitat models for the cheetah in the refuge. The model was used to determine desirable habitats and factors affecting the desirability of cheetah habitat using the maximum entropy method.

\section{Materials and Methods}

\section{Materials}

\section{Study area and population}

Dareh Anjir Wildlife Refuge is located in Yazd province in Iran, has an area of $1753.2 \mathrm{ha}$, and is located at $32^{\circ} 10^{\prime} \mathrm{N}$ to $32^{\circ} 36^{\prime} \mathrm{N}$ longitude and $54^{\circ} 48^{\prime} \mathrm{E}$ to $55^{\circ} 32^{\prime} \mathrm{E}$ latitude (Fig. 1).

The tallest peaks in this region are the Dareh Anjir, Chah Joleh, Adhero, Saghand, and Sobusi mountains. Altitude ranges from $830 \mathrm{~m}$ to $2293 \mathrm{~m}$. Plains and flatlands are spread across the whole region. The mean annual precipitation is $74.9 \mathrm{~mm}$ and the mean daily temperature is $19.1^{\circ} \mathrm{C}$. Based on the Ambrezh identification, Dareh Anjir has a dry 
and cold climate; and based on the Domarten correlation, the area has a dry climate (Consulting Engineer Corp. of Iran, 2009).

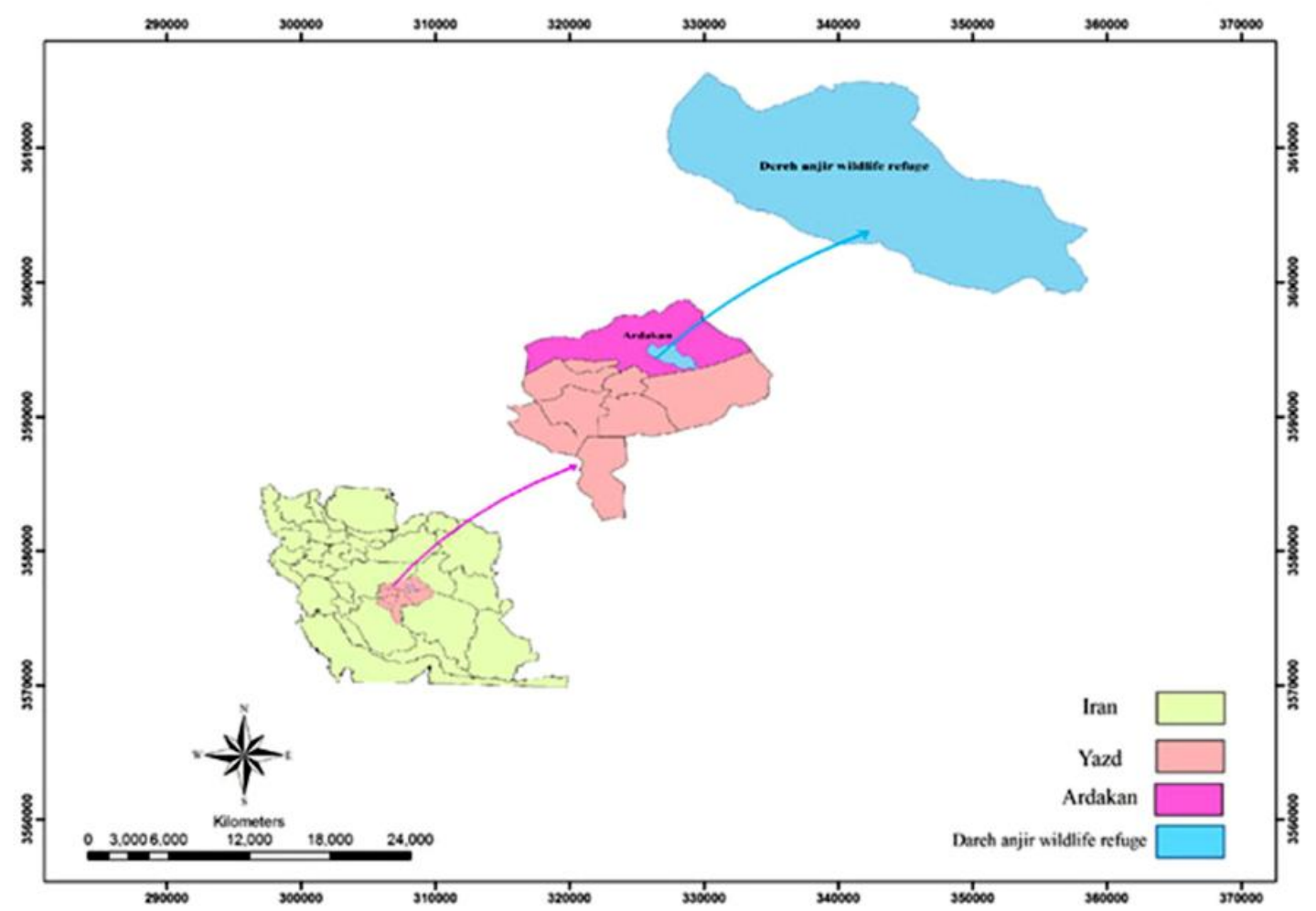

Figure 1. Map of Dare-Anjir Wildlife Refuge and its location in Iran.

Dareh Anjir wildlife refuge has no continuously-flowing river. Water reservoirs in this region are often brackish. The few freshwater sources are mainly wells, springs and stone channels (qanat) (Abedini, 2009). The wildlife refuge is located in the central Iran zone and exhibits the typical geologic, petrologic, and tectonic specifications of the region (Consulting Engineer Corporation of Iran, 2009). There are 138 species from 36 families and 112 genera in the area, including 13 protected species. The main plants of the area include: Artemisia sieberi، Zygophyllum eurypterum ‘ Astragalus sp ، Pteropyrum aucheri، Calligonum bungei، Acantholimon sp ‘ Seidlitzia rosmarinus، Tamarix sp، Lxiolirion tataricum، Ephedra strobilacea ammoniacu (Consulting engineer Corporation of Iran-Vegetation, 2009). Aside from Acinonyx jubatus venaticus, other valueable species such as wild sheep Ovis orientalis and jebeer Gazella bennettii and wild goat Capra aegagrus and wolf Canis lupus, golden jackal Canis aureus, fox Vulpes vulpes, wild cat Felis silvestris, leopard Panthera pardus and golden eagle Aquila chrysaetos, Aquila rapax, Falco peregrines, live in this region(Abedini, 2009). The use of trap cameras and a capture program in 2010 confirmed the presence of about 5 cheetahs in Dareh Anjir wildlife refuge (Zamani, 2010).

\section{Methods}

This study used the maximum entropy method and MAXENT software to produce a habitat desirability model and Arc GIS software to determine correlations and information layers for MAXENT. MAXENT combines environmental variables and 
species presence points and produces random points for the foreground, then presents a species distribution model with accompanying statistics and diagrams as output. Indirect variables such as slope, direction, elevation, slopes, type of habitat, and geology were collected across the desert regions and used to produce good indications of species dispersion patterns. Guisam and Zimmermann (2000) believe that these variables are suitable substitutions for a combination of species resources, and direct and indirect variables. Since the present study was performed across 1753.2 ha, indirect variables that present a better estimation about species presence were used for modeling. Information needed for MAXENT can be divided into two groups that include species presence register points and information layers of predictive environmental variables:

- Species presence points: these points are used as dependent variables and include species presence points on the regional level. Cheetah presence points were determined based on direct observation, photography by trap cameras, and traces such as feces, paw prints, and resting places for 2011-2012. The coordinates of these points were registered using GPS units at 39 points. They were then saved in CSV format in Excel and prepared for entry into MAXENT.

- Predictive environmental variables: These included behavioral and ecological features of the cheetahs, interviews with experts and wildlife rangers, and 11 independent habitat variables (elevation, slope, direction, water resources, vegetation, prey distribution, unpaved roads, asphalt roads, railways, mines, villages) that affect species presence were used for modeling. Raster plans were created in ASCII format in Arc GIS9.3 for use as environmental variables in MAXENT.

Information layers for elevation, slope and geographical direction were obtained from regional line maps prepared using a digital elevation model (DEM). Freshwater sources were wells, springs and stone channels (qanat) that provide water required for wildlife. The results of previous studies and the present study identified three species as preferential prey for the cheetah: Gazella bennettii, ovis orientalis and capra aegagrus. To prepare the information layer for prey, presence maps for the three species were produced separately in a polygonal vector shape and then the maps were combined into one map with the number of prey specified in each pixel. Studies have shown that the Dareh Anjir wildlife refuge provides good shelter and good vegetation for the herbivore cheetah prey.Predictive variables of human interaction in the Dareh Anjir wildlife refuge and were villages, roads (unpaved, asphalt), mines, and railroads (Figure 2). The villages include Saghand village on the eastern boundary and the Moghestan villages (Olia, Sofla) near the northeastern boundary. Additional residential compounds exist to the southeast for the major mineral and industrial center at Chadormalu. The access roads into Dareh Anjir wildlife refuge are the YazdTabas asphalt highway, and the Chadormalu-Saghand and Kharanaq asphalt roads. Human activity on the region level includes mines, railroads, and railroad stations that decrease habitat security and have a degrading effect on wildlife and their habitats. A uranium mine is located in the region of Chah Joleh mountain and is under the jurisdiction of the Atomic Energy Organization. Chadormalu iron ore mine is also located in this region. The railroads in the region are the Ardakan-Chadormalu, Chadormalu-Ardakan, and the Ardakan-Bafq railways.

This study used the maximum entropy method and MAXENT software to produce a habitat desirability model and Arc GIS software to determine correlations and 
information layers for MAXENT. MAXENT combines environmental variables and species presence points and produces random points for the foreground, then presents a species distribution model with accompanying statistics and diagrams as output. Indirect variables such as slope, direction, elevation, slopes, type of habitat, and geology were collected across the desert regions and used to produce good indications of species dispersion patterns. Guisam and Zimmermann (2000) believe that these variables are suitable substitutions for a combination of species resources, and direct and indirect variables. Since the present study was performed across 1753.2 ha, indirect variables that present a better estimation about species presence were used for modeling.

Information needed for MAXENT can be divided into two groups that include species presence register points and information layers of predictive environmental variables:

- Species presence points: these points are used as dependent variables and include species presence points on the regional level. Cheetah presence points were determined based on direct observation, photography by trap cameras, and traces such as feces, paw prints, and resting places for 2011-2012. The coordinates of these points were registered using GPS units at 39 points. They were then saved in CSV format in Excel and prepared for entry into MAXENT.

- Predictive environmental variables: These included behavioral and ecological features of the cheetahs, interviews with experts and wildlife rangers, and 11 independent habitat variables (elevation, slope, direction, water resources, vegetation, prey distribution, unpaved roads, asphalt roads, railways, mines, villages) that affect species presence were used for modeling. Raster plans were created in ASCII format in Arc GIS9.3 for use as environmental variables in MAXENT.

Information layers for elevation, slope and geographical direction were obtained from regional line maps prepared using a digital elevation model (DEM). Freshwater sources were wells, springs and stone channels (qanat) that provide water required for wildlife. The results of previous studies and the present study identified three species as preferential prey for the cheetah: Gazella bennettii, ovis orientalis and capra aegagrus. To prepare the information layer for prey, presence maps for the three species were produced separately in a polygonal vector shape and then the maps were combined into one map with the number of prey specified in each pixel. Studies have shown that the Dareh Anjir wildlife refuge provides good shelter and good vegetation for the herbivore cheetah prey. Predictive variables of human interaction in the Dareh Anjir wildlife refuge and were villages, roads (unpaved, asphalt), mines, and railroads (Fig. 2). The villages include Saghand village on the eastern boundary and the Moghestan villages (Olia, Sofla) near the northeastern boundary. Additional residential compounds exist to the southeast for the major mineral and industrial center at Chadormalu.

The access roads into Dareh Anjir wildlife refuge are the Yazd-Tabas asphalt highway, and the Chadormalu-Saghand and Kharanaq asphalt roads. Human activity on the region level includes mines, railroads, and railroad stations that decrease habitat security and have a degrading effect on wildlife and their habitats. A uranium mine is located in the region of Chah Joleh mountain and is under the jurisdiction of the Atomic Energy Organization. Chadormalu iron ore mine is also located in this region. The railroads in the region are the Ardakan-Chadormalu, Chadormalu-Ardakan, and the Ardakan-Bafq railways. 


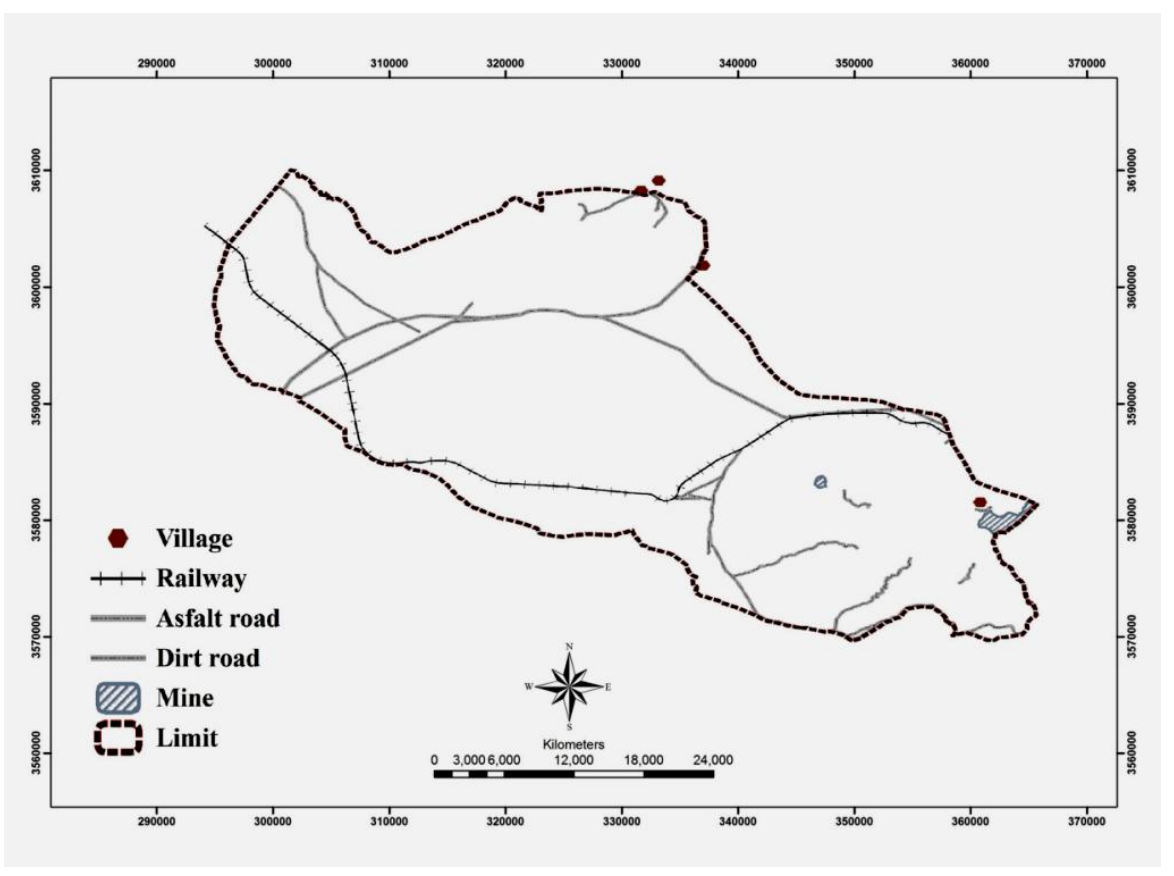

Figure 2.Map of human-made factor in Dareh Anjir wildlife refuge

MAXENT information layers for elevation, slope, direction, distance from water resources, and distance from human activity (villages, roads, mines, railroads) are continuous predictive variables and information layers on prey and vegetation are categorical predictive variables. Cell size was $30 \times 30 \mathrm{~mm}$ for all Raster maps; since the maps should overlap, a digital elevation map was used as a reference to make the layers isometric. before MAXENT analysis, it was necessary to prepare the Raster maps for successive analyses and overlapping. These processes include:

- Normality of data: The maximum entropy method is sensitive to normality and equality of primary data (coordinates, line and column numbers, resolution). If this principle is not considered, calculations deviate and produce unreliable output, thus, all plans were equalized into one form in Arc GIS using the spatial analyst tool multivariate command.

- Data correlation: MAXENT requires variables that do not correlate; when two variables are highly dependent, both appear in the final model with one coefficient. When two or more variables have a correlation of more than 0.8 , it is necessary to omit one variable from MAXENT. This done in Arc GIS using the spatial analyst tool multivariate command. Since the correlation between all environmental variables was less than 0.8 , none were omitted.

- Since prey and water reservoirs attract carnivores, and villages, mines, roads and railroads deter wildlife, the distance command in Arc GIS was used to enter these factor maps into analysis.

MAXENT, version 3.3.3, was used to model maximum entropy of the geographical distribution of species to predict potential regions for the presence of cheetahs. Species presence data and predictive variables were entered into analysis. Two groups of presence data (test and training) were included in the random sampling to properly evaluate the model. Studies show that test data should consider $25 \%$ to $30 \%$ of presence 
data and that training data should consider $70 \%$ to $75 \%$ of presence data: $70 \%$ of presence points were randomly used to build a model and the remaining $30 \%$ was used to evaluate the results of the model. For random sampling, cross validation was repeated 10 times. Output parameters produced by the model were:

- Cheetah.html: The main output file which contains statistical calculations, maps, model's image and other links of the file.

- Cheetah s.asc: including the plan predicted with ascii format.

- Cheetah.png: including predicted distribution image.

- Plot: including different maps and graphs to print and use in reports.

In MAXENT, it is possible to calculate the area under the receiver operating characteristic (ROC) curve to evaluate model performance. This curve is represented as a graph where the vertical axis represents sensitivity (true positive) and the horizontal axis represents specificity (false positives). The area under curve (AUC) is created from the sensitivity and feature values and is a quantitative indicator of the efficiency and predictive power of the model. The range of values for the AUC is the lowest permitted value of 0.5 (random prediction) to 1.0 (completely accurate prediction) (Fielding and Bell 1997, Phillips et al. 2006).

\section{Results}

The model was created using MAXENT and the 39 presence records for one year and environmental records for different areas.

\section{$A U C$}

A value of 0.5 is the lowest value allowed for AUC. When AUC approaches 1.0, it means that the blue and green lines are far from the black line. Figure 3 shows the maximum entropy algorithm used to model performance using the ROC curve. As shown, the AUC is 0.95 for the training data and 0.89 for the test data. The maximum entropy algorithm was very good and significant at the $p<0.001$ level for predicting the presence of cheetahs.

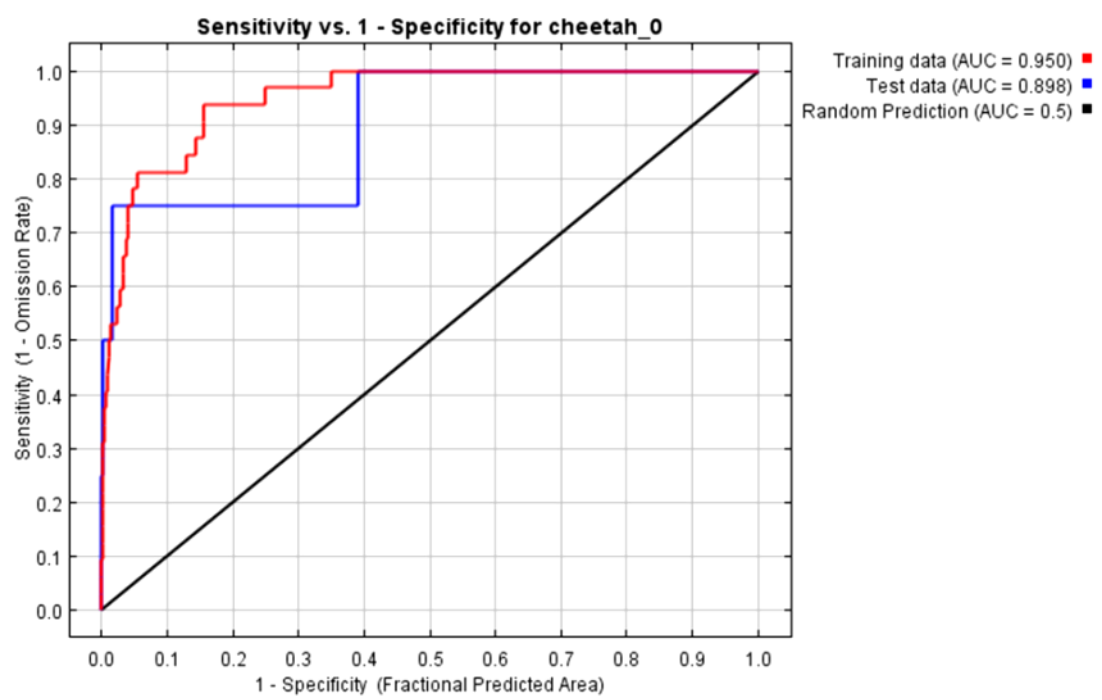

Figure 3. ROC curve calculated for the presence of Cheetah in Dareh Anjir 
The jackknife feature in MAXENT shows the importance of an environmental variable and the impact on model efficacy of the a variable that is removed or stands alone. Jackknife for AUC was greater for the gradient variable, perhaps because cheetah presence points declined at high gradients (Fig. 4).

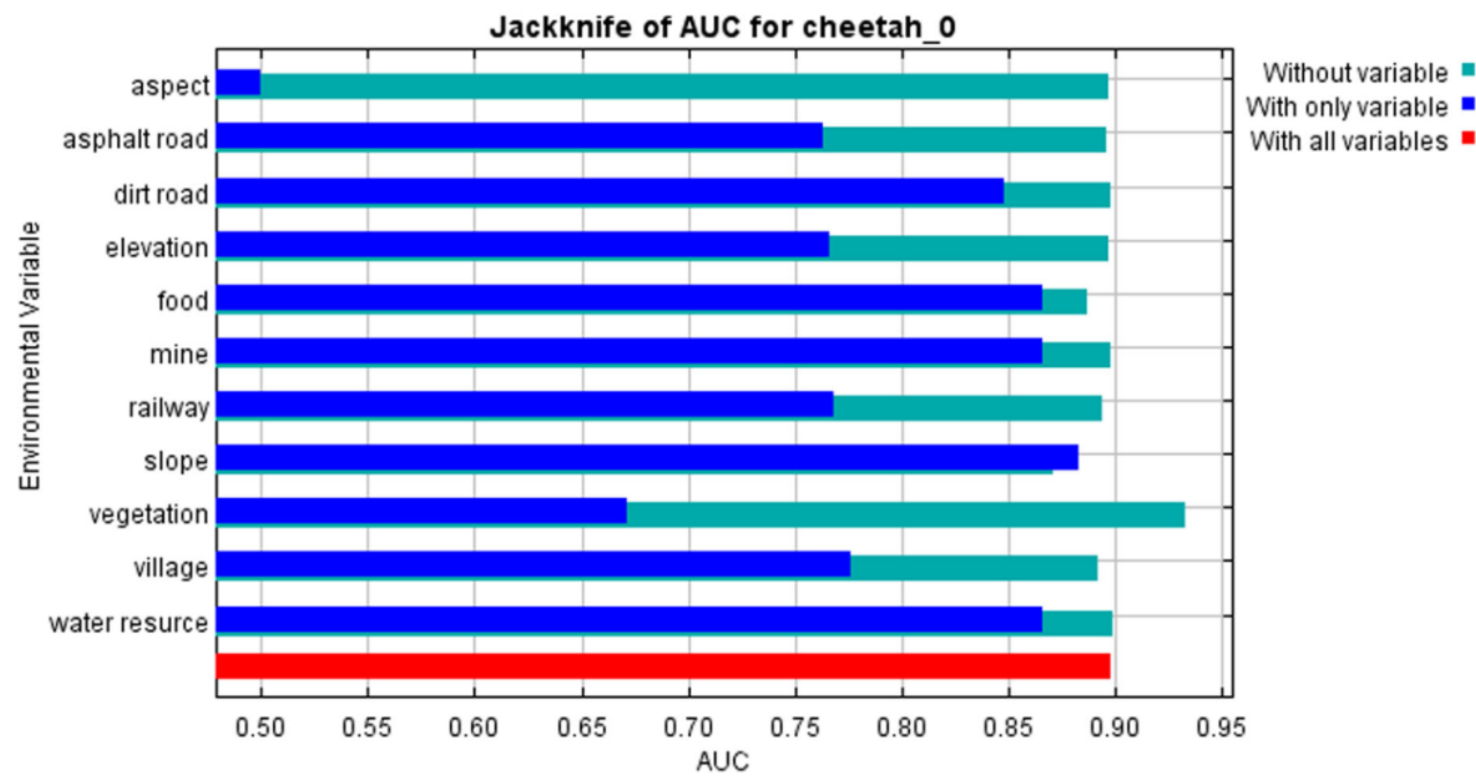

Figure 4.Test of Jackknife, the area under the curve for environmental variables in Dareh Anjir

MAXENT specifies the relative contribution of each variable. The results of the maximum entropy algorithm indicates that the distance-to-water-reservoir variable had the greatest relative contribution $(45 \%)$ and permutation importance $(40.2 \%)$ and was the most effective non-biological parameter for species distribution and prediction map creation. Distance-to-water-reservoir was assigned $45 \%$ of total change, indicating the usefulness of this variable. The second most effective parameter was prey distribution (13.4\% of total change), and the third most effective parameter was vegetation (12\% of total change); other variables contributed from $0.0 \%$ to $12 \%$ (Table 1).

Table1. Relative contribution of the independent variables to the MaxEnt model

\begin{tabular}{c|c|c}
\hline Variables & Percent contribution & Permutation Importance \\
\hline Water resource & 45 & 40.2 \\
\hline Food & 13.4 & 15.9 \\
\hline Vegetation & 12 & 10.1 \\
\hline Slope & 11 & 3.3 \\
\hline Dirt road & 10.8 & 4.8 \\
\hline Railway & 3.8 & 12.6 \\
\hline Asphalt road & 2.7 & 11.5 \\
\hline Village & 1 & 0.9 \\
\hline Mine & 0.3 & 0.7 \\
\hline Elevation & 0 & 0 \\
\hline Aspect & 0 & 0
\end{tabular}


According to jackknife, for both test and training data, the environmental variable that showed the most value when used separately was distance-to-water-reservoir (Fig. 5).
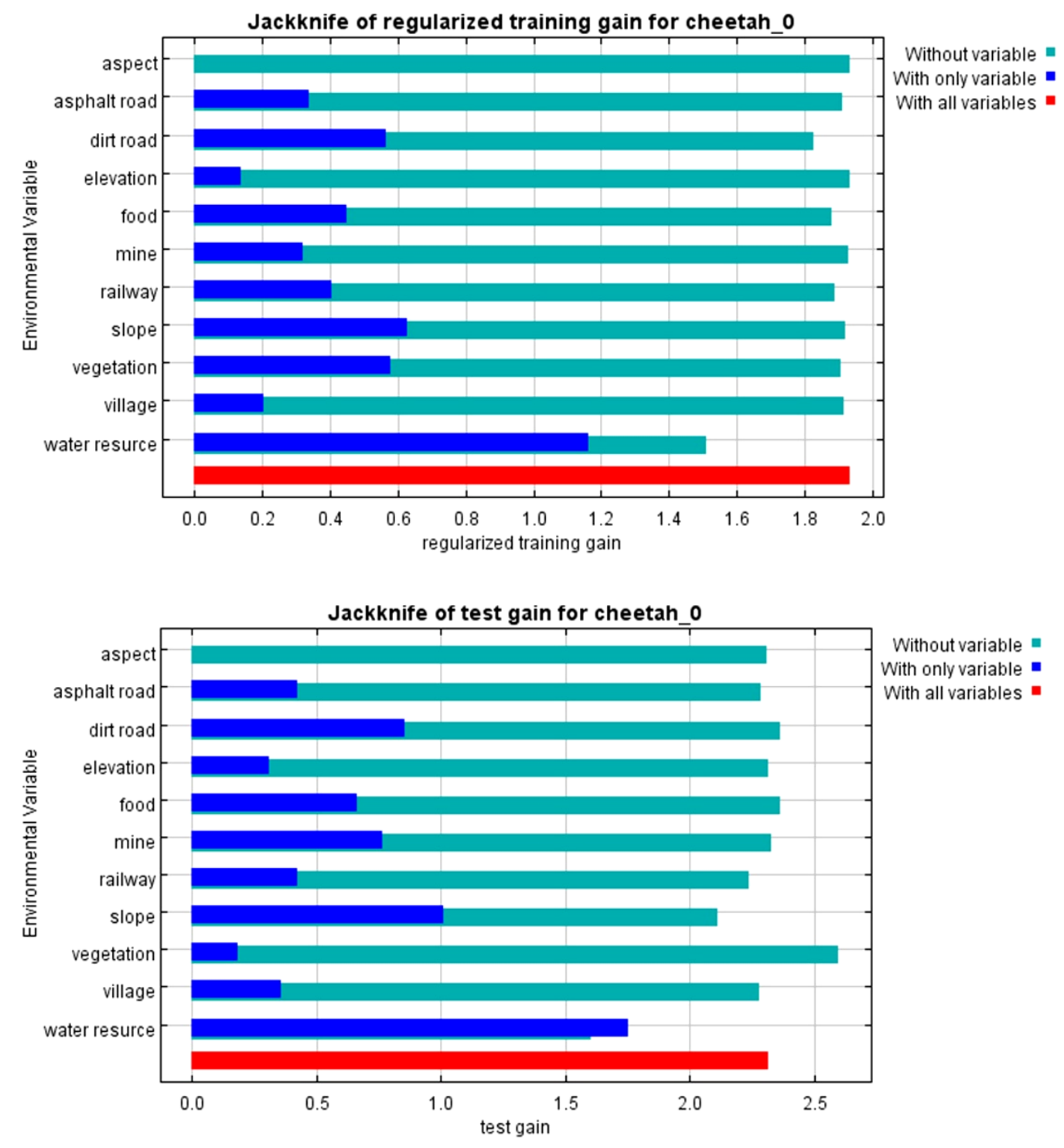

Figure 5.Jack nife test for test and training presence data

\section{Analysis of omission/commission}

A cumulative diagram shows the omission error for the test and training data. The omission error, or false negative (less than the real value or omission rate), occurs when a species is definitively observed to exist in one place, but the model indicates that the species does not exist in that location. On the graph, the black line is that produced by MAXENT for which the error value is zero. The green line is the error value for test data and the blue line is the error value for training data. When the blue or green line is located under and close to the black line, the error value decreases and the better the result. The value of the omission error for the training data in this study was lower than that for the test data. Analysis of the omission rate and predicted area as a function of 
the cumulative threshold (Philips et al., 2005) showed that the omission rate was close to the predicted area omission rate, indicating the model is robust for further analysis (Fig. 6).

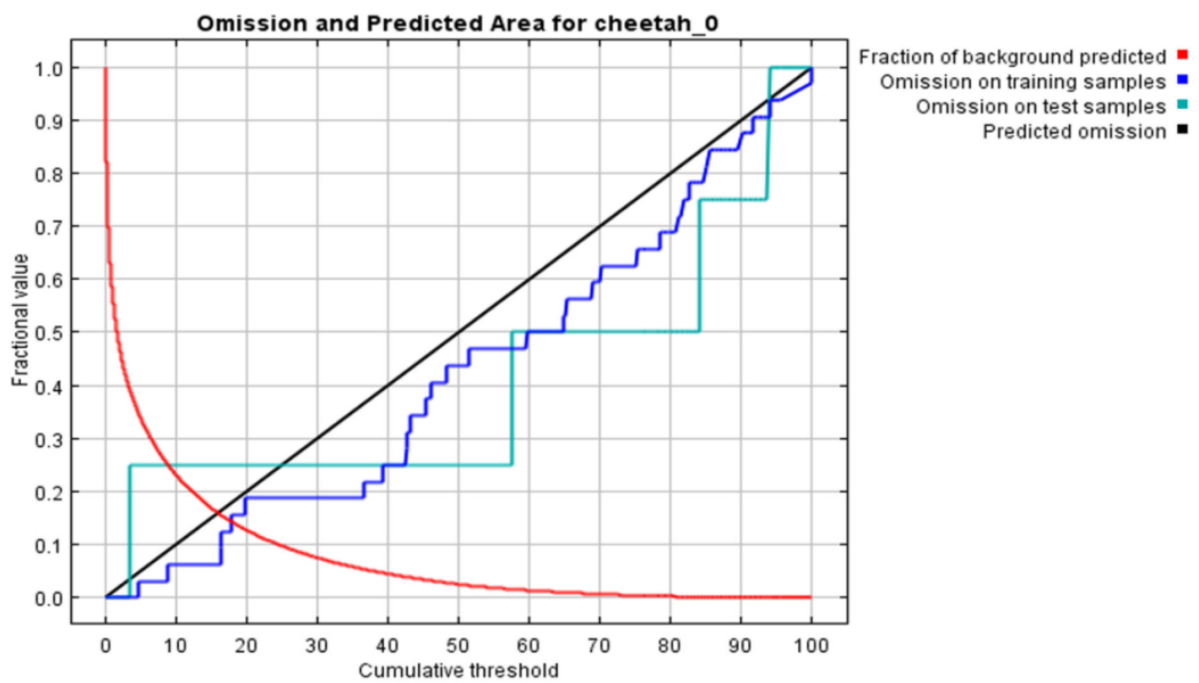

Figure 6. Omission rate and predicted area as a function of the cumulative threshold

\section{Cheetah.png the map of habitat desirability}

The map of habitat desirability in Dareh Anjir wildlife refuge varied from zero to one (Fig.7). Very desirable areas with a high probability of cheetah presence are shown in red; locations where the probable presence of cheetahs is zero are shown in blue, and places where the probable presence cheetahs varies from $38 \%$ to $69 \%$ are shown in green.

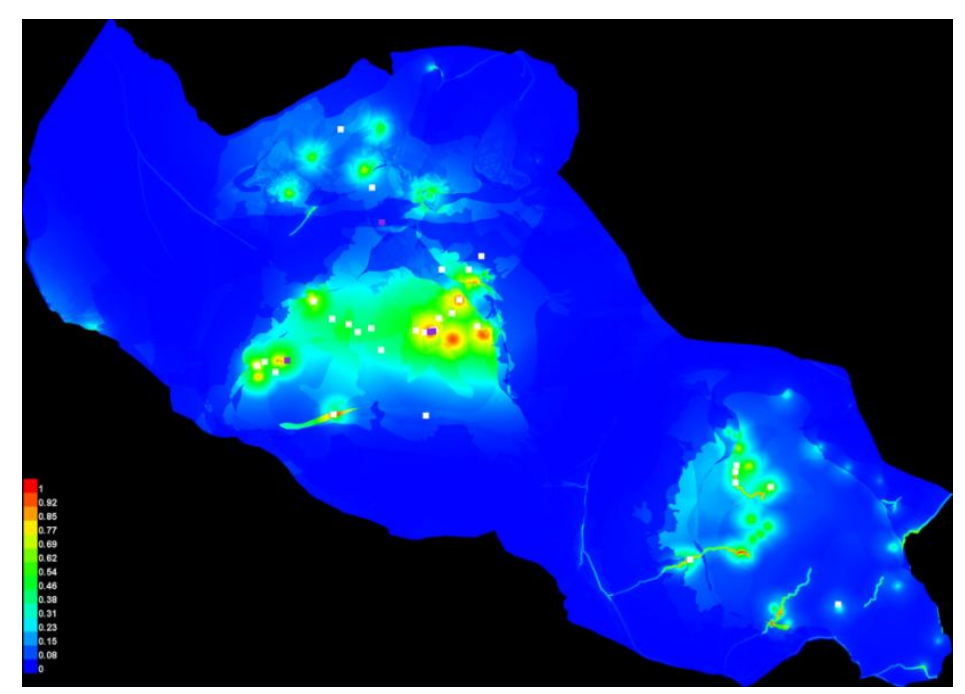

Figure 7.MaxEnt habitat suitability map (Dareh Anjir Wildlife Refuge)

The maps were then classified again according to the threshold of possible observation of the species under the study. This was is based on investigation and expert opinion and the desirability of habitat was classified as desirable or undesirable. 
Locations with a probability of $0 \%$ to $14 \%$ observation of cheetahs was classified as undesirable and the regions with a probability of $14 \%$ to $100 \%$ was desirable (Fig 8).

Desirable areas are those areas known to be used by cheetahs or that have the potential of being occupied by cheetahs. This classification indicated that 27837 ha of Dareh Anjir wildlife refuge is desirable and the remaining 147465 ha were undesirable areas for the presence of cheetahs.

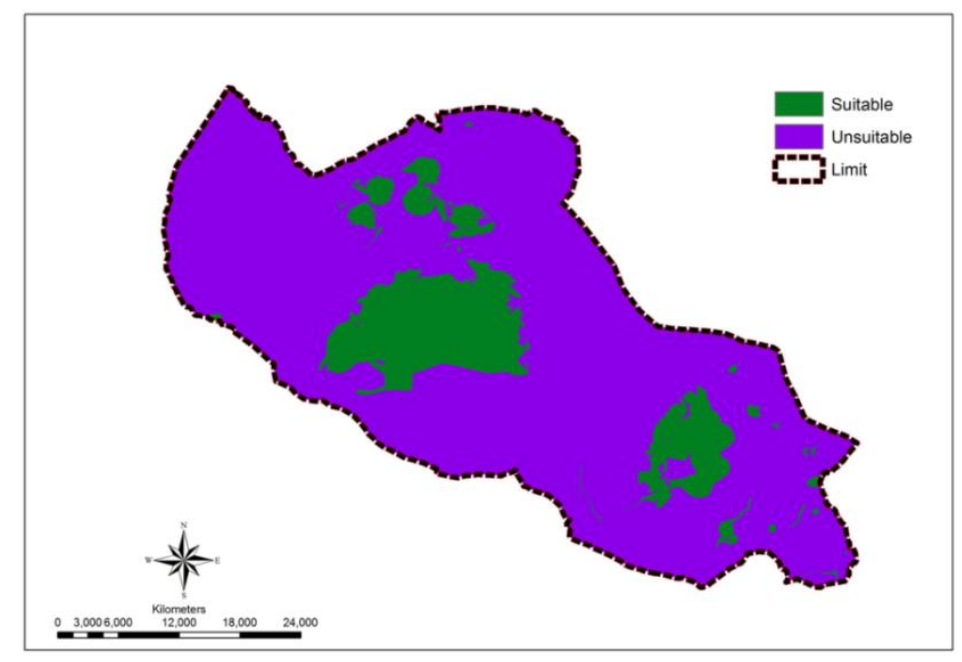

Figure 8. Suitable and Unsuitable habitats for Cheetah in Dareh Anjir Wildlife Refuge

\section{Discussion}

Identification of potentially desirable areas for the existence of Asiatic cheetahs is an important step toward preserving these animals. Dareh Anjir wildlife refuge is a major habitat for the Asiatic cheetah in Iran, but this model can also be used for other habitats in this region. The results of modeling with the maximum entropy algorithm for the species in Dareh Anjir wildlife refuge made it clear that the most important factor in determining and increasing desirable habitats for Asiatic cheetah is distance-to-waterreservoirs.

Omidi et al. (2010) estimated the appropriate altitude and gradient for a desirable habitat for the pardus saxicolor panther in Esfahan's Kola Ghazi national park was 1800 $\mathrm{m}$ to $2400 \mathrm{~m}$ in altitude at $20 \%$ to $70 \%$ gradients using the ENFA method. The interpretation of the habitat desirability map show that the most desirable cheetah habitat is located in Dareh Anjir wildlife refuge between $1000 \mathrm{~m}$ and $2200 \mathrm{~m}$ with gradients of $0 \%-65 \%$. The maximum entropy algorithm predictions indicate that the central, north and southeastern portions of Dareh Anjir wildlife refuge have highest probability of cheetah presence. Table 1 shows that three parameters (distance-to-waterreservoir, prey distribution, vegetation) were most effective for increasing habitat fit and predicting desirable locations for the presence of cheetahs in Dareh Anjir wildlife refuge. Of the three, distance-to-water-reservoir was the most significant factor for prediction of desirable regions for the presence of cheetahs. There are 166 ha of water reservoirs in desirable areas and 23 ha in undesirable areas. Since this variable increases the probability of cheetah presence and in recognition of the droughts of recent years in this area, undesirable areas can be prioritized for maintaining good conditions for the water reservoirs using managerial strategies. 
When the desirable habitat map is compared to that showing water reservoir distribution points, it is clear that areas for the highest desirability for cheetahs have the most water reservoirs, indicating the correspondence of the model with actual conditions for habitat. The continuous variable response curve for distance-to-waterreservoir indicates that the greater the distance-to-water-reservoir for an area, the lower the possibility of observing cheetahs in that area (Fig. 9).

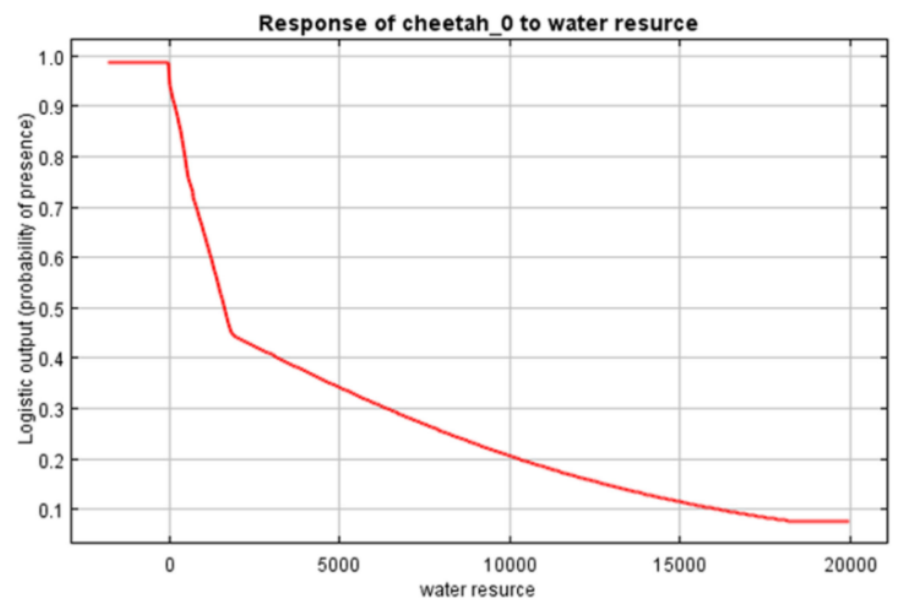

Figure 9. Continuous environmental variable response curve for distance-to-water-reservoir for the probability of observing cheetahs in Dareh Anjir area.

Recent studies show three herbivore species are major and preferential cheetah prey (Zamani, 2010; Conservation of Asiatic Cheetah and its Habitats, 2008). Unfortunately, the degradation and decrease in their natural habitats and poaching has decreased their number which, in turn, decreased the likelihood of the presence of cheetahs. In the areas of Dareh Anjir refuge with abundant populations of prey, the likelihood of observing cheetahs and potential habitat increased. The response curve for the categorical variable of prey shows that locations where all three types of prey exist have an increased probability of observing cheetahs (Fig. 10)

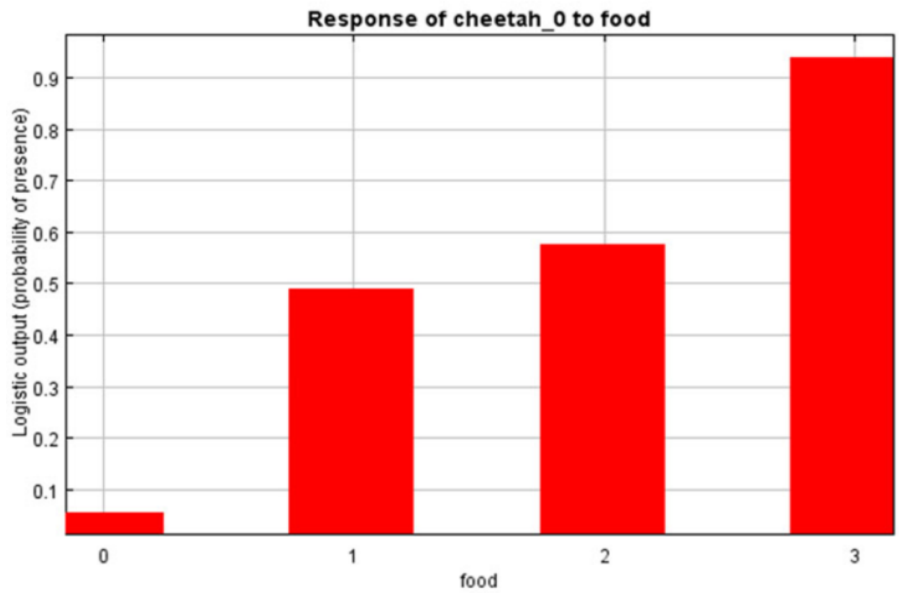

Figure 10.Categorical environmental variable response curves for prey distribution and predicted observation of cheetahs in Dareh Anjir area. 
Vegetation is one important factor that increases habitat desirability and the probability of the presence of cheetahs in an area. Vegetation is a food for cheetah prey and can shelter cheetahs, thus, any area having suitable vegetation is a desirable habitat. In regions with vegetation, areas with the presence of Artemisia sieberi-Zygophyllum are the most desirable habitats for cheetahs and the probability of cheetah presence is high in such areas.

The conformity of this model was confirmed by comparing observed conditions for cheetahs in the past 10 years with the most desirable modeled classes of habitat. Most of these observations are located in the areas where there is an overlap of desirable classes of habitat. It can be concluded that the existing habitat for cheetahs in Dareh Anjir wildlife refuge is greater than what currently used by this species. If this area is wellmanaged, it should be possible to increase the number of cheetahs existing in this area (Fig. 11).

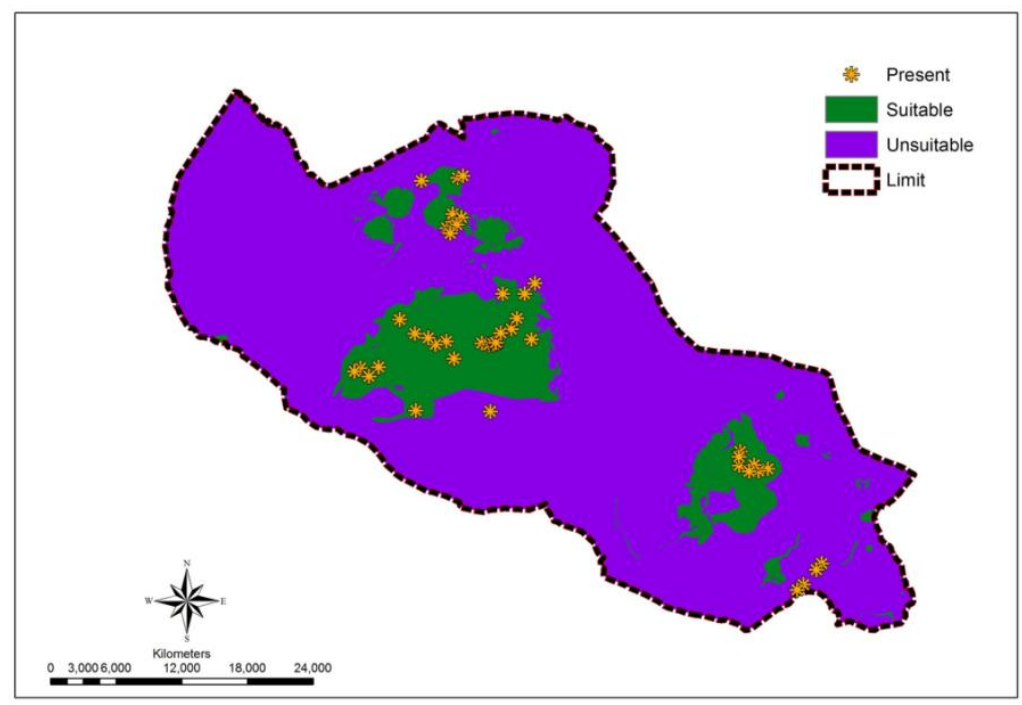

Figure 11. Suitable and Unsuitable habitats and presence points for Cheetah in Dareh Anjir Wildlife Refuge

\section{Conclusion}

Evaluating potential habitats for cheetahs is one of the most important steps toward the conservation of the cheetah and helps managers and authorities identify and conserve more suitable areas. The value of the proposed model and its conclusion are a result of the maps that were formulated. Each pixel of these maps has a special value by which similar modeling of other area can be performed to design good conservation management for many species and their habitats. The large industrial and mineral iron facility at Chadormalu is located inside Dareh Anjir wildlife refuge and is near known desirable habitats. It is important to control the activities of this center to mitigate its bad effects on these desirable habitats.

Reports from the general environment conservation office indicate that the existence of roads is a major factor threatening cheetahs, as proven by the number of cheetahs killed by automobiles in Dareh Anjir wildlife refuge. The best way to resolve this problem is to relocate roads from inside the park to outside the area and deploy warning signs along the roadways. Since many alternate routes exist around and inside Dareh 
Anjir wildlife refuge, the general environment conservation office points to the control of the entry of non-residents, particularly hunters, into the area. This requires an increase in the number of guards, especially in busy areas and the provision of facilities for this task.

The area has very hot and dry summers; this variable can be controlled by assuring adequate water resources in desirable cheetah habitats. The simplest way to increase desirable habitats for the cheetah in the study region is to improve management of water sources and create more sources of water sources in these habitats. It is recommended that modeling desirable habitats should be used in all projects designed to increase and protect Iranian wildlife species. Using these models, managers can identify controllable and important environmental variables that have the greatest effect on desirable habitats for these species. The identification of desirable habitats allows the creation of new and increasing populations.

Acknowledgements. We would like to thank the Iran Department of Environment particularly the Yazd provincial office, for giving of management support for this study. We gratefully acknowledge efforts of game guards of Dareh Anjir Wildlife Refuge, who assisted us in the field.

\section{REFERENCES}

[1] Abedini, M. (2009): Dareh Anjir wildlife refuge certificate, the general environment conservation office in yazd province .-Yazd Department of Environment Publishing, Iran.

[2] Anderson, M. C., Watts, M. J., Freilich, J.E., Yool, S.R., Wakefield, G.I., Mccaulery, J.F, Fahnestock A.(2000): Regression-tree modeling of desert tortoise habitat in the centeral Mojave. - Ecological Applications 10(3):890-900.

[3] Baldwin, R.A. ( 2009): Use of maximum entropy modeling in wildlife research.-Entropy 11(85): 4-555.

[4] Consulting engineer Corporation of Iran. (2009): Studies Management Plan of Dareh Anjir Wildlife Refuge, Report Number (6): Vegetation.

[5] Consulting engineer Corporation of Iran. (2009): Studies Management Plan of Dareh Anjir Wildlife Refuge, Report Number (4): Climate and weather

[6] Consulting engineer Corporation of Iran. (2009): Studies Management Plan of Dareh Anjir Wildlife Refuge, Report Number (2): geology and geomorphology.

[7] Fielding, A.H., Bell, J.F. (1997): A review of methods for the assessment of prediction errors in conservation presence/absence models.-Environmental Conservation 24: 49-38.

[8] Giovanelli, J.G.R., DeSiqueira, M.F., Haddad, C.FB, Alexandrino, J. (2010): Modeling a spatially restricted distribution in the Neotropics: how the size of calibration area affects the performance of five presence-only methods.-Ecological Modelling 221: 224-215.

[9] Guisan, A., Zimmermann, N.E. (2000): Predictive habitat distribution models in ecology.- Ecological Modelling 135:147-186.

[10] Harrington, F.A. (1971): Present status of the cheetah in Iran.Unpublished typescript report.

[11] Hoffman, J.D., Narumalani, S., Mishra, D.R., Merani, P., Wilson, R.G. (2008): Predicting potential occurrence and spread of invasive plant species along the north Platte river, Nebraska. -Invasive Plant Science and Management 1(4): 367-359.

[12] Leung, B., Lodge, D.M., Finnoff, D., Shogren, J.F., Lewis, M.A., Lamberti, G. (2002): An ounce of prevention or a pound of cure: bioeconomic risk analysis of invasive species.- Proc Biol Sci. 269(1508): 2407-2413. 
[13] Levins, R. (1966): The strategy of model building in population ecology.-American. Scientist 421:421-431.

[14] Mack, E.L., Firbank, L.G., Bellar, P.E., Hinsley, Y.S.A, Veitch, N. (1997): The comparison of remotely sensed and ground-based habitat area data using species-area models. - Applid ecology 34:1222-1228.

[15] Morrison, M.L., Marcot, B.G., Mannan, R.W. (1992): Wildlife-habitat relationships:Concepts and applications. - University of Wisconsin Press, Madison,Wisconsin,USA.

[16] Naturalium, R. (2009): The impact of habitat fragmentation by anthropogenic infrastructures on wolves(Canis lupus). PhD Thesis. Biology and Biotechnology group. Ruhr-University of Bochum. 115p.

[17] Kaboli,O. M., M., Karami, M., Mahini, A. S., Hasanzadeh Kiabi B. (2010): Habitat suitability modelin of Panthera pardus saxicolor by ENFA in Kolahghazi.-Journal of environment sicence and technology 12(1):137-148.

[18] Phillips, S.J., Anderson, R.P., Schapire, R.E. ( 2006): Maximum entropy modeling of species geographic distributions.- Ecological Modelling 190: 259-231.

[19] The project for conserving Asian cheetah and its related habitats. (2008): the report of operation and achievements, September 2001 upto September 2008, p:13,65,79.

[20] Treves A, Jurewicz, R.R., Naughton-Treves, L., Rose, R.A., Willging, R.C., Wydeven, A.P. (2002): Wolf depredation on domestic animals: control and compensation in Wisconsin.-Wildlife Society Bulletin 30: 241-231.

[21] Vantoor, M.L., Jaberg, C., Safi, K. (2011): Integrating sex-specific habitat use for conservation using habitat suitability models.-Animal Conservation 14:512-520.

[22] Wilting, A., Cord, A., Hearn, A.J., Hesse, D., Mohamed, A., Traeholdt, C., Cheyne, S.M., Sunarto, S., Jayasilan, M.A., Ross, J., Shapiro, A . C., Sebastian, A., Dech, S., Sanderson, C., Sanderson, J., Duckworth, J.W., Hofer, H. (2010): Modelling the species distribution of flat- headed cats (Prionailurus planiceps), an endangered south-east Asian small felid. -Plos One 5(3): e9612.

[23] Zamani, N. (2010): A comparison study on food habits of Asiatic cheetah in Naibandan and Darreh-Anjer wildlife refuge,Yazd Iran. -MSc thesis. University of Tehran,(in Persian) 